\title{
Prevalence of Overweight, Obesity, and Dietary Behaviors among Adolescents in Dubai Schools: A Complex Design Survey 2019
}

\author{
Mona Abdullatif Kadhim AlAbady Ayesha Altheeb Fidaa Rishmawi \\ Hana Jaradat Sobya Farooq \\ Programs \& Studies, Public Health Protection Department, Dubai Healthcare Corporation, Dubai Health Authority, \\ Dubai, UAE
}

\section{Keywords}

Adolescents health - Overweight - Obesity - Risk behaviors . Prevalence - UAE - Gulf Cooperation Council · Public health . Population study

\begin{abstract}
Background: Overweight and obesity in adolescence have become a public health challenge. Health effects due to overweight and obesity appear during adolescence and continue into adulthood. Modifiable factors associated with overweight and obesity include unhealthy dietary behaviors and lack of exercise. Assessment of the prevalence of overweight and obesity and unhealthy dietary behaviors is essential to plan for preventive programs at the population level. Objectives: The aim of the study was to estimate the prevalence of overweight, obesity, and unhealthy dietary behaviors among adolescents of grades 8-12 in Dubai schools, 2019. Method: The Adolescents Risk Behavioral Survey (ARBS) is a 2-stage stratified cluster study. The 1st stage involved randomly selecting schools with a probability proportional to the size and the 2 nd stage was randomly selecting classes, and all students in the selected classes were invited to participate; the total participants were 1,683 adoles-
\end{abstract}

karger@karger.com www.karger.com/dmj

Karger $\stackrel{\text { ' }}{5}$

GOPEN ACCESS
(C) 2021 The Author(s)

Published by S. Karger AG, Basel

This is an Open Access article licensed under the Creative Commons Attribution-NonCommercial-4.0 International License (CC BY-NC) (http://www.karger.com/Services/OpenAccessLicense), applicable to the online version of the article only. Usage and distribution for commercial purposes requires written permission. cents from grades 8-12 from 28 private and government schools. Students answered a self-administrated electronic questionnaire. Anthropometric measures including height and weight were assessed by a trained school nurse. Body mass index was calculated and classified according to World Health Organization (WHO) growth charts for sex and age. Data were analyzed with adjustment for weight, primary sampling unit, and stratum. Results: Among the adolescents of Dubai schools studying in grades 8-12, the prevalence of overweight was $25.3 \%$ (95\% confidence interval [Cl]: $22.7-$ $28.2)$ and obesity was $15 \%$ (95\% Cl: 13.0-18.9). Overweight did not vary between male and female students, but obesity was higher among male students $19.9 \%$ (95\% Cl: 15.4-25.1) than female students $11.8 \%$ (95\% Cl: 8.7-15.6) ( $p=0.0261)$. Age and grade were not found to be associated with overweight or obesity. The prevalence of unhealthy dietary behaviors was common. Examining dietary habits from 30 days prior to the survey, $21.3 \%$ of adolescents (95\% Cl: 17.2-26.1) reported not eating fruits and $19.7 \%(95 \% \mathrm{Cl}$ : 15.7-24.4) not eating vegetables. With regard to consuming dairy, $3.3 \%$ of adolescents (95\% Cl: 10.9-16.1) did not drink milk or consume dairy products in the 7 days prior to the survey, $31 \%$ of adolescents (95\% Cl: 26.8-35.5) consumed a carbonated drink daily, and $18.4 \%$ did not eat breakfast on all 7 days dur-
Correspondence to:

Mona Abdullatif, maomar@dha.gov.ae 
ing and before the survey. Eating fast food was high among adolescents as $78.9 \%$ reported eating fast food one or more days in the week preceding the survey. Conclusion: School programs for overweight and obesity need further strengthening and to extend their scope to outside of the school community.

(c) 2021 The Author(s)

Published by S. Karger AG, Basel

\section{Introduction}

Worldwide, overweight and obesity during childhood and adolescence have become a public health challenge [1] with major contribution to the global burden of disease [2]. In 2016, the global prevalence of overweight and obesity among children and adolescents aged 5-19 years had reached approximately $18 \%$ [3].

Regionally, the prevalence of overweight and obesity among school-age children and adolescents appears to have reached alarming levels among the Gulf Cooperation Council (GCC) countries [4]. The prevalence of overweight reached up to $38.4 \%$ in the UAE [5], $48.2 \%$ in Kuwait [6], 29.0\% in Oman [7], and 38.6\% in Bahrain [8] and that of obesity was reported to be $16.6 \%$ in the UAE [5], 23.2\% in Kuwait [6], 12.5\% in Oman [7] and 17.9\% in Bahrain [8].

Although adolescents (age-group between 10 and 19 years) [9] are considered healthy by nature, biological, social, and psychological changes they experience can have health consequences during adolescence potentially impacting the entire life-course [10]. The development of overweight and obesity during adolescence can have an immediate negative health effect, which can continue into adulthood [11]. Severe obesity (body mass index [BMI] $\geq 40$ ) is known to be a risk factor for serious and potentially life-threatening complications, including diabetes, hypertension, hyperlipidemia, asthma, and arthritis $[12,13]$.

Adolescents' overweight and obesity are assessed using BMI, which is a practically inexpensive and a noninvasive anthropometric tool based on height and weight [14]. BMI is charted on growth charts with references for age and sex. As per the World Health Organization (WHO), pediatric age-groups, including adolescents up to 19 years old are assessed for thinness, normal weight, overweight, and obesity by charting their BMI on growth charts. A BMI falling $<-2$ SD from median is classified as underweight, BMI between $>-2$ SD to $<1$ SD from median is normal weight, $\mathrm{BMI}$ falling $>+1 \mathrm{SD}$ from median is overweight and findings $\mathrm{BMI}$ falling $>+2 \mathrm{SD}$ from median is considered obese [15].
Several studies found that overweight and obesity among adolescents were associated with modifiable factors such as dietary behaviors, including an increased number of meals eaten outside the home, larger portion sizes of meals at restaurants and fast-food takeaways, increased consumption of soft drinks, diet composition such as high-fat and low-carbohydrate intakes and lower intake of fruits and vegetables $[12,16]$, along with sedentary lifestyles like low rates of physical activity and highscreen activities like watching television $[17,18]$. Some studies found that the sociodemographic factors associated with overweight were gender, family history of obesity, and socioeconomic level [19].

Over the past 10 years, the Dubai Health Authority (DHA) has made great strides toward improving health to prevent overweight and obesity among students in Dubai. The DHA along with the Ministry of Health and Prevention mandates that all schools apply the overweight and obesity screening program. School clinics inside each school annually measure height and weight of students and calculate the BMI according to reference growth charts. Parents of students screened positive for overweight or obesity are alerted by the school clinic [20-23].

All schools in Dubai are mandated to follow the school nutritional policy and guideline developed by the DHA in 2011. The school nutritional policy and guideline banned the sale of highly concentrated sugary drinks, carbonated drinks, energy drinks, and high-sugar content foods such as chocolate and candy in the school canteen. The policy also encouraged healthy food options [24]. A policy update in 2017 extended the list of banned food to include items with a high content of saturated fats, artificial flavors, mono-sodium, and sodium, such as chips, processed meats, such as sausages, mortadella, pastrami, and instant noodles [25].

Assessing the prevalence of overweight, obesity, and modifiable risk factors is essential in planning for preventive and interventional programs at the population level. Findings from this study can help in planning evidencebased public health interventions targeting adolescents at a time in their life when they are amenable to develop knowledge and skills needed to live a healthy adulthood $[26,27]$.

\section{Methodology}

The objective of this survey was to study the prevalence of overweight, obesity, and the prevalence of some unhealthy dietary behaviors among adolescents in the schools of Dubai. This study was part of the Adolescent Risk Behavior Survey Dubai-2019 (ARBS- 
Dubai-2019) carried out across governmental and private schools of Dubai in the 2018-2019 academic year. ARBS-Dubai-2019 is a complex design cross-sectional survey with a 2-stage stratified random cluster sample design.

Inclusion criteria for schools were any school in Dubai having classes in any of the following grades $8,9,10,11$, or 12 . Inclusion criteria for students were all students in the randomly selected classes. The exclusion criteria were no student assent, no parental consent, or student absent on day of the survey.

\section{Sample Size}

Since the ARBS measures several unrelated estimates, the best approach was to estimate the sample size based on measuring reliably characteristics held by $30 \%$ of students with a $5 \%$ margin-of-error for each of the targets. ARBS-Dubai-2019 used Probability Proportional to Size sampling methods to achieve a self-weighting sample. The sample was calculated using Proportion for Cluster Surveys as part of Epi-info online version 7.02.27. The total sample required 1,723 students, taking into consideration the following parameters:

- Total population size in grades 8-12 in Dubai: 104,856 students.

- Standard error $=0.05$

- Analysis of subgroups will increase sample size by a factor equal to needed domains, which is 2 corresponding to gender and/or grade level.

- Design effect (Deff) $=2$.

- Anticipated nonresponse rate was $20 \%$ based on similar previous studies conducted in the UAE.

- $Z$ statistic defining the level of desired confidence was 1.95 for 95\% confidence interval (CI).

- Average number of students in the class was 20 students.

Inclusion criteria was any school having one class or more from any of the following grades: $8,9,10,11$, or 12 . Sample stratification was based on 2 criteria including (a) male, female, and mixed schools and (b) lower grade classes 8 and 9 and higher grade classes 10,11 , and 12 .

In terms of sampling stages, the 1st stage was randomly selecting schools with a probability proportional to the school enrollment size. Hence, schools were the primary sampling units. The total number of schools surveyed was 28 (both private and government). The 2 nd stage was selecting classes from schools using a simple random method. Based on enrollment size of the school, the randomly selected classes were 2,4 , or 8 classes. The total number of surveyed classes was 100, divided between lower and higher grades. All students in the randomly selected class were invited to participate in the survey.

The survey questionnaire was adapted from the Youth Risk Behavior Survey (YRBS) developed by the Centers for Disease Control and Prevention (CDC), USA. The questionnaire was translated and validated by a group of experts from the Public Health Protection Department - DHA. The English questionnaire used local dialectic English; it was translated into the Arabic language then translated back to English. An expert group checked the face validity. The group included epidemiologists, school health consultant, and public health research specialists. Both Arabic and English versions were piloted on adolescent students before the survey was conducted [5]. Survey administrators were trained for fieldwork and any additional assistance required on the questionnaire.

Anthropometrics, including height and weight were measured by a trained school health nurse according to standardized proce- dures, using calibrated tools in the school clinic. Weight was measured with minimal clothing after removing footwear using a calibrated electronic weighing scale in the school clinic, weight was recorded in kilograms to the last $100 \mathrm{~g}$. Height was measured using a calibrated school clinic stadiometer, standing height after removing footwear was recorded in centimeters to the last completed 0.1 $\mathrm{cm}$.

The study received ethical approval from the Dubai Scientific Research Committee. Survey procedures were designed to protect student privacy by allowing anonymous and voluntary participation. Parents gave informed consent for their child to participate prior to the survey day. Participating students were assented on the day of the survey with electronic forms. Those who gave no assent or parental consent was absent were excluded from participation.

\section{Statistical Analysis}

The data set was cleaned and edited for inconsistencies. Stata 12 software was used to compute weighted prevalence estimates and the statistical analysis. Weighting was applied to each question/response to reflect the likelihood of sampling each student and to reduce bias by compensating for differing patterns of nonresponse. The weight used for estimation was reached by $W=\mathrm{W} 1$ $\times \mathrm{W} 2 \times \mathrm{f} 1 \times \mathrm{f} 2$, where $\mathrm{W} 1=$ the inverse of the probability of selecting the school, W2 = the inverse of the probability of selecting the classroom within the school, $\mathrm{fl}=$ nonresponse adjustment factor, and $\mathrm{f} 2$ = a post-stratification adjustment factor calculated by grade. Accordingly, all presented results were weighted. Adjusted Wald test was used to check differences between groups according to sex and grade. A $p$ value $<0.05$ was the cut-off level for significance.

Standard errors are usually reported in typical tables of complex survey design to better interpret CI width and overlap when comparing 2 estimates [28]. However, we opted to report Deff, instead of standard error because it serves 2 objectives.

Deff is the ratio of variance for percentages obtained from our complex design survey to the variance of a similar percentage obtained from a survey with a simple random sample of the same size. Deff represents the combined effect of stratification, clustering, and weighting used for adjustment of nonresponse and unequal selection probabilities present in complex survey designs [29] such as ours. The objective of reporting Deff was first to provide researchers wanting to run a similar study with a complex design sample like ours with more information when selecting a suitable Deff for calculating sample size. Second, readers can interpret the difference between the reported percentages with its CIs as to whether there is an overlap or not if Deft is known. As presented in the following formula; Deft is a function of Deff.

$$
\begin{aligned}
& \text { Deft }=\sqrt{\text { Deff }} \\
& \text { Deff }=\frac{\text { SE }(\text { Estimate from the designed implemented surevy })}{\text { SE (Estimate from SRS with same number of sample elements })}
\end{aligned}
$$

Deff can be simply converted to Deft by square rooting. Example if Deff is 4 then Deft $=\sqrt{4}=2$, indicating that the standard error and consequently the $\mathrm{CI}$ is 2 times wider than what would have been obtained if the survey used a simple random sample of the same size. Hence, the reader must be cautious when interpreting significant differences between percentages with statistically significant $p$ values and a Deft $>3$.

Adolescent BMI classification for underweight, normal weight, overweight, and obesity were classified based on WHO-2017 BMI 
Table 1. Adolescents in grades $8-12$ by demographics in Dubai, 2019

\begin{tabular}{lll}
\hline Gender & Number $(n=1,683)$ & Weighted \% $(95 \% \mathrm{Cl})$ \\
\hline $\begin{array}{l}\text { Female } \\
\text { Male }\end{array}$ & 820 & $51.7(45.07-58.2)$ \\
Age, years & 863 & $48.3(41.8-54.9)$ \\
12 & 94 & $3.3(1.9-5.4)$ \\
13 & 343 & $15.6(11.4-21.0)$ \\
14 & 419 & $21.9(17.4-27.2)$ \\
15 & 323 & $21.5(15.7-28.7)$ \\
16 & 254 & $18.8(15.1-23.3)$ \\
17 & 196 & $15.2(11.0-20.7)$ \\
18 & 54 & $3.7(2.0-6.6)$ \\
Grades & & \\
8 & 505 & $23.3(15.8-33.0)$ \\
9 & 462 & $20.7(13.6-30.2)$ \\
10 & 209 & $19.9(11.9-31.3)$ \\
11 & 291 & $18.2(12.7-25.5)$ \\
12 & 216 & $17.9(10.6-28.7)$ \\
\hline
\end{tabular}

$\mathrm{Cl}$, confidence interval.

growth charts for age and sex [12]. WHO definitions were used as following: underweight was a $\mathrm{BMI}<-2 \mathrm{SD}$ from median, normal weight was a $\mathrm{BMI}>-2 \mathrm{SD}-<1 \mathrm{SD}$ from median, overweight was $\mathrm{BMI}>+1 \mathrm{SD}$ from median and obesity a BMI $>+2$ SD from median $[30,31]$.

\section{Results}

A total number of 28 schools from both government and private sectors were selected from which 1,683 adolescent students grades 8-12 agreed to participate in the ARBS-2019. The school response rate was $75.7 \%$, the student response rate was $98.6 \%$, and the overall response rate was $74.6 \%$. ARBS-2019 data are representative of all adolescents attending grades $8,9,10,11$, and 12 in Dubai schools. The sample showed an equal representation of sex, where female students accounted for $51.7 \%$ of the sample and male students $48.3 \%$.

The participants falling within the age-group 13 to $<18$ years constituted $93 \%$ of the sample. The survey sample contained only $3.3 \%$ of adolescents, aged 12 years and only $3.7 \%$ aged 18 years (Table 1). The sample had a balanced grade representation with 8 th grade constituting $23.3 \%$, 9th grade students $20.7 \%$, 10th grade students $19.9 \%$, 11 th grade students $18.2 \%$, and 12 th grade students $17.9 \%$ (Table 1). Based on BMI for age and sex, the study found the prevalence of underweight among adolescents was $2.6 \%$ (95\% CI: 1.8-3.6), overweight was
Table 2. Adolescents in grades $8-12$ by BMI classification in Dubai, 2019

\begin{tabular}{lll}
\hline BMI classification & Number $(n=1,683)$ & Weighted \% (95\% Cl) \\
\hline Underweight & 47 & $2.6(1.5-3.6)$ \\
Normal weight & 929 & $56.4(52.4-60.5)$ \\
Overweight & 425 & $25.3(22.7-28.2)$ \\
Obesity & 282 & $15.7(13.0-18.9)$ \\
\hline Total & 1,683 & 100 \\
\hline
\end{tabular}

$\mathrm{Cl}$, confidence interval; $\mathrm{BMI}$, body mass index.

$25.3 \%$ (95\% CI: $22.7-28.2$ ), while obesity prevalence was $15.7 \%$ (13.0-18.9) (Table 2).

Obesity prevalence was higher among male students than female students (19.9 and $11.8 \%$, respectively) and this difference was found to be statistically significant. On the contrary, the prevalence of overweight among female students was higher than male students (27.2 and 23.3\%, respectively) but this difference was statistically not significant. Overweight and obesity did not differ between different age-groups (Table 3).

When comparing overweight and obesity between grades, the prevalence of overweight for adolescents in grades $8-10$ was slightly higher than adolescents in grades 11-12 (26 and $24.1 \%$, respectively) but the difference was not statistically significant. Obesity between the 2 groups was almost similar with $15.5 \%$ for grades $8-10$ and $16 \%$ for grades 11-12 (Table 3).

For the prevalence of dietary behaviors, ARBS-2019 studied consumption of fruits, vegetables, and dairy. Moreover, adolescents were asked about consumption of high concentration sugary drinks, such as fizzy drinks and fast food. Table 4 displays the prevalence of dietary behaviors by gender and grades.

ARBS-2019 found that in the 30 days prior to the survey, $21.3 \%$ of adolescents had not consumed any fruit or $100 \%$ fruit juices; excluding soda, sports drinks, or other fruit-flavored drinks. The results varied between male (19.4\%) and female students (23.1\%) but the difference was not significant. The percentage was slightly higher among younger adolescents enrolled in grades 8-10 than students in grades $11-12$ (21.8\% for grades $8-10$ and $20.3 \%$ for grades $11-12$ ).

Overall, $19.7 \%$ of the students in grades $8-12$ had not eaten vegetables that is, green salad, carrots, potatoes, or other vegetables (not counting french fries, fried potatoes, or potato chips) during the 30 days before the survey. In contrast to fruit consumption, more male students
Dubai Med J 2022;5:1-9 DOI: $10.1159 / 000519863$
Abdullatif/AlAbady/Altheeb/Rishmawi/ Jaradat/Farooq 
Table 3. BMI classification by demographics among adolescents in grades 8-12, Dubai-2019

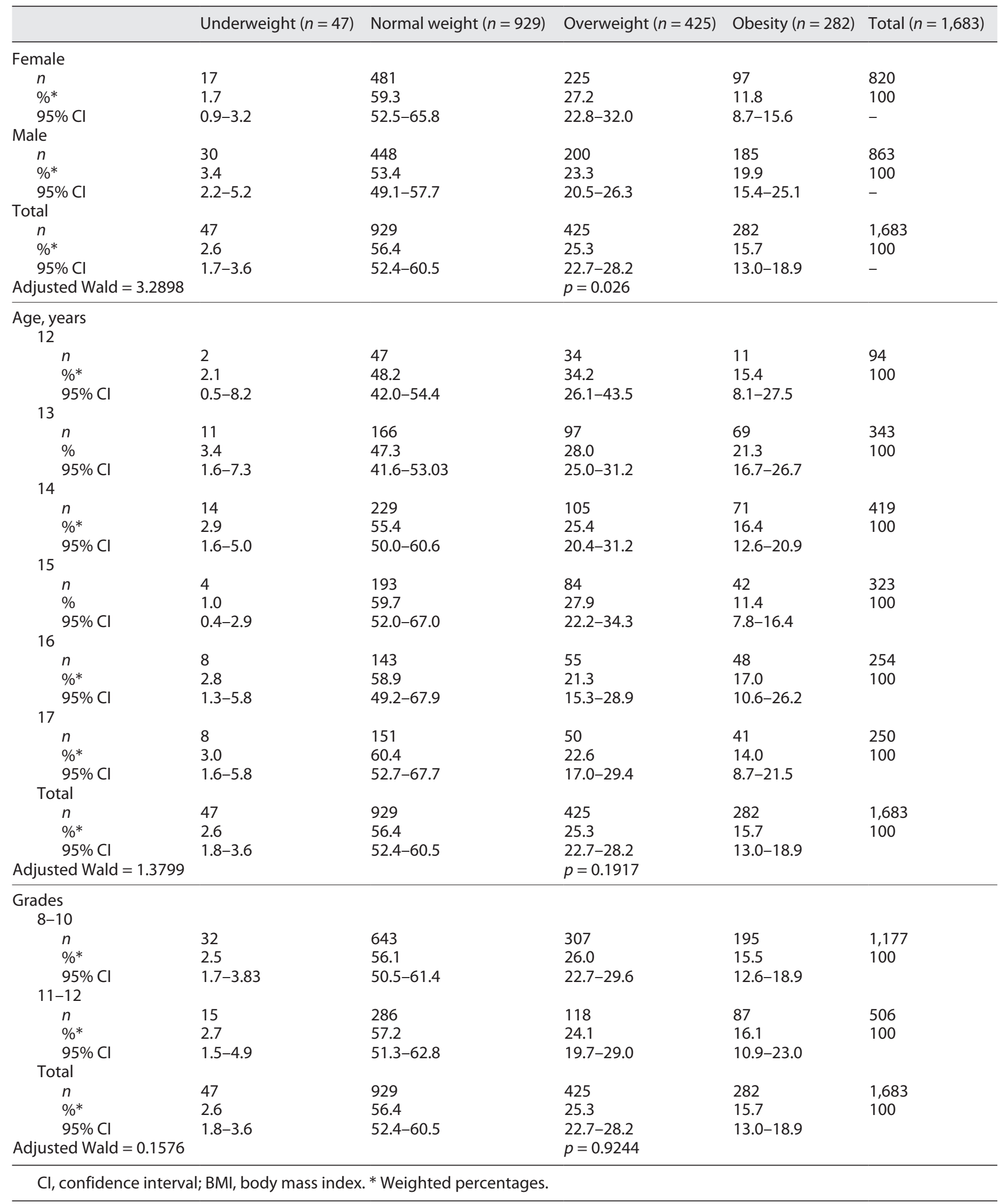


Table 4. Dietary behaviors by sex and grade among adolescents in grades 8-12, Dubai-2019

\begin{tabular}{|c|c|c|c|c|c|c|}
\hline $\begin{array}{l}\text { Did not eat fruit or drink } 100 \% \text { fruit } \\
\text { juices (during the past } 30 \text { days) }\end{array}$ & $\begin{array}{l}n \\
\% * \\
95 \% \mathrm{Cl} \\
\text { A Wald ( } \\
\text { Deff }\end{array}$ & $\begin{array}{l}365 \\
21.3 \\
17.2-26.1 \\
\text { e) }\end{array}$ & $\begin{array}{l}177 \\
19.4 \\
13.6-26.8 \\
\text { A. Wald = } \\
\text { Deff = 5.0 }\end{array}$ & $\begin{aligned} & 189 \\
& 23.1 \\
& 17.6-29.7 \\
= & 0.4086)\end{aligned}$ & $\begin{array}{l}255 \\
21.8 \\
16.9-27.8 \\
\text { A. Wald =0.0 } \\
\text { Deff = 5.1 }\end{array}$ & $\begin{array}{l}111 \\
20.3 \\
13.6-29.3 \\
=0.8670)\end{array}$ \\
\hline $\begin{array}{l}\text { Did not eat vegetables } \\
\text { (during the past } 30 \text { days) }\end{array}$ & $\begin{array}{l}n \\
\text { \%* } \\
95 \% \mathrm{Cl} \\
\text { A Wald ( } \\
\text { Deff }\end{array}$ & $\begin{array}{l}343 \\
19.7 \\
15.7-24.4 \\
\text { e) }\end{array}$ & $\begin{array}{l}191 \\
21.8 \\
16.7-28.0 \\
\text { A. Wald = } \\
\text { Deff }=4.9\end{array}$ & $\begin{array}{l}152 \\
17.7 \\
12.1-25.2 \\
=0.3456)\end{array}$ & $\begin{array}{l}255 \\
21.3 \\
16.2-27.5 \\
\text { A. Wald =0.6 } \\
\text { Deff }=4.9\end{array}$ & $\begin{array}{l}88 \\
16.8 \\
11.0-24.9 \\
=0.3101)\end{array}$ \\
\hline $\begin{array}{l}\text { Drank carbonated soft drinks one or } \\
\text { more times per day (during the past } \\
30 \text { days) }\end{array}$ & $\begin{array}{l}n \\
\text { \%* } \\
95 \% \mathrm{Cl} \\
\text { A Wald ( } \\
\text { Deff }\end{array}$ & $\begin{array}{l}509 \\
31.0 \\
26.8-35.5 \\
\text { e) }\end{array}$ & $\begin{array}{l}306 \\
37.3 \\
32.0-43.0 \\
\text { A. Wald = } \\
\text { Deff = 3.3 }\end{array}$ & $\begin{array}{l}203 \\
25 \\
19.5-31.5 \\
=0.0065)\end{array}$ & $\begin{array}{l}360 \\
31.5 \\
26.0-37.7 \\
\text { A. Wald =0.2 } \\
\text { Deff }=3.2\end{array}$ & $\begin{array}{l}149 \\
29.9 \\
24.1-36.4 \\
=0.6474)\end{array}$ \\
\hline $\begin{array}{l}\text { Did not eat breakfast on all } 7 \text { days } \\
\text { (during the past } 7 \text { days) }\end{array}$ & $\begin{array}{l}n \\
\% * \\
95 \% \mathrm{Cl} \\
\text { A Wald ( } \\
\text { Deff }\end{array}$ & $\begin{array}{l}297 \\
18.4 \\
14.3-23.2 \\
\text { e) }\end{array}$ & $\begin{array}{l}146 \\
17.4 \\
11.3-25.8 \\
\text { A. Wald = } \\
\text { Deff = 5.6 }\end{array}$ & $\begin{array}{l}151 \\
19.3 \\
14.5-25.2 \\
=0.666)\end{array}$ & $\begin{array}{l}224 \\
20.2 \\
15.1-26.4 \\
\text { A. Wald = } 1.3 \\
\text { Deff }=5.2264\end{array}$ & $\begin{array}{l}73 \\
15.0 \\
9.3-23.45 \\
=0.2619)\end{array}$ \\
\hline
\end{tabular}

A. Wald, adjusted Wald; Deff, design effect; $\mathrm{Cl}$, confidence interval. * Weighted percentages.

reported not eating vegetables than female students (21.8 and $17.7 \%$, respectively) but this difference was statistically not significant. More students in grades $8-10$ had not eaten vegetables than students in grades $11-12(21.3$, and $16.8 \%$ respectively).

In terms of dairy intake, $13.3 \%$ of the adolescents had not drunk milk or consumed dairy products (counting milk in a glass or cup, from a carton, yoghurt, labnah, cheese, and laban) during the 7 days before the survey. More female students had not consumed dairy than male students $(15.6 \%$ for female students and $10.7 \%$ for male students), but there was no significant statistical difference between them.
For consumption of carbonated soft drinks, such as a can, bottle, or glass of carbonated soft drinks without counting diet soda during the 7 days before the survey, $31 \%$ of adolescents reported drinking carbonated drinks daily. Male students showed a statistically significant higher rate than female students (37.3\% for male and 25\% for females). The comparison between students in grades 8-10 and grades $11-12$ showed almost equal results (31.5 and $29.9 \%$, respectively).

With regard to eating breakfast, in the 7 days prior to the survey, $18.4 \%$ of adolescents had not eaten breakfast on any of the 7 days. A higher percentage of female adolescents than male adolescents had not eaten breakfast on 
all 7 days (19.3\% vs. $17.4 \%)$ and a higher percentage among adolescents in grades 8-10 than adolescents in grades $11-12(20.2 \%$ vs. $15.1 \%)$. There was no significant difference between female and male adolescents or between grades.

A total of 1,313 participants $(78.9 \%)$ ate fast food for one or more days during the past 7 days prior to the survey. The percentage was $76.8 \%$ in male and $80.9 \%$ in female students. The percentage for students in grades 8-10 was $79.2 \%$, and the percentage for students in grades $11-$ 12 was $78 \%$. However, these differences were not significant.

\section{Discussion}

This is the 1st ARBS at the level of the Emirate of Dubai studying overweight, obesity, and nutritional behaviors. The survey revealed the prevalence of overweight and obesity among adolescents aged 13 to $<18$ years was lower than national and regional levels. In Dubai, $2.6 \%$ of adolescents were underweight lower than the national level of 3.6\% in the UAE-2016 [5]. Similarly, underweight rates among the same age-group in other regional countries were 3.1\% (2.0-4.8) [6] in Kuwait-2015, 6.7\% (5.58.3) [7] in Oman-2015, and 5.2\% (4.2-6.3) [8] in Bahrain-2016.

Overweight was also lower at the national level; in Dubai, it was $25.3 \%$ compared to $38.4 \%$ at the national level. The prevalence of obesity in Dubai was similar to the national level and neighboring Oman. In Dubai, obesity among adolescents reached $15.7 \%$, while at the national level, it was $16.6 \%$ [5], and in Oman-2015, it was $12.5 \%$ [7]. However, compared to other countries in the region, obesity among adolescents in Dubai was lower than $23.19 \%$ in Kuwait-2015 [6] and $17.9 \%$ in Bahrain-2016 [8]. In Dubai, age and grade were not found to be associated with overweight and obesity. Although no difference was observed in the prevalence of overweight between male and female students, differences in the prevalence of obesity were significant between male and female students. Obesity was significantly higher among male adolescents 19.9\% (95\% CI: 15.4-25.1) than female adolescents $11.8 \%$ (95\% CI: 8.7-15.6) $(p=0.0261)$. Similar differences were observed at the national level [29] and in neighboring countries with higher per capita gross domestic product countries, such as Kuwait [30] and Saudi Arabia [32], but no difference was found in relatively lower gross domestic product countries, such as Oman [31] and Bahrain [32]. Possible explanations for this differ-

Prevalence of Overweight, Obesity, and Dietary Behaviors among Adolescents ence beside the difference in lifestyles and dietary behaviors between female and male adolescents are the likelihood that female adolescents at this age might be more concerned with their physical appearance and body image than their male counterparts. For dietary behaviors among adolescents, ARBS-2019 focused on consumption of fruits, vegetables, and dairy, as well as consumption of high-concentration sugary drinks, such as fizzy drinks and fast food.

Fruits and vegetables are important components of a healthy diet. Reduced fruit and vegetable intake is linked to poor health and increased risk of non-communicable diseases. Current evidence indicates that fruits and vegetables consumed as part of the daily diet can help reduce the risk of coronary heart disease, stroke, and certain types of cancer [33]. The WHO recommends at least 400 $\mathrm{g}$ (i.e., 5 portions) of fruits and vegetables per day, excluding potatoes, sweet potatoes, cassava, and other starchy roots [34].

Our study found during the 30 days prior to the survey $21.3 \%$ (95\% CI: 17.2-26.1) of adolescents had not eaten fruits and 19.7\% (95\% CI: 15.7-24.4) had not eaten vegetables. There were no significant difference in rates between male and female adolescents nor between lower (8-10) and higher grades (11-12).

Milk is an important source of many nutrients, including calcium. There is evidence that intake of milk and milk products is associated with bone health in children and adolescents $[35,36]$ and a lower risk of cardiovascular disease [37, 38], type 2 diabetes, and lower blood pressure in adults [39]. The recommended intake of milk and milk products is 3 cups per day for adolescents [40]. ARBS-2019 found that during the 7 days prior to the survey, $13.3 \%$ (95\% CI: 10.9-16.1) had not consumed milk or dairy products. No difference was found across sex or grades.

ARBS-2019 found 31\% (95\% CI: 26.8-35.5) of adolescents drank carbonated drinks daily. Significantly, more male adolescents exhibited this behavior 37.3\% (95\% CI: $32-43$ ) than female adolescents $25 \%$ (95\% CI: 19.5-31.5). Consumption of sugar-sweetened beverages is associated with a less healthy diet, dental decay [41], and an increased risk of being overweight [42] among children and the development of metabolic syndrome and type 2 diabetes [43].

Eating breakfast is associated with weight loss and weight loss maintenance, improved nutrient intake, and better cognitive function, academic performance [44], and school attendance rates [45]. Among adolescents in Dubai schools, $18.4 \%$ had not eaten breakfast on all 7 days 
before the survey. Eating fast food was high among adolescents: 78.9\% reported eating fast foods on one or more days during the week preceding the survey.

A major strength of the study was biometric measurements of body weight and height were taken by a trained nurse and BMI calculation and classification was based on WHO reference growth charts of 2017. Another strength of the study was that the survey used a Webbased questionnaire known to produce better quality data than the conventional pencil and paper questionnaire prone to data entry errors.

ARBS-Dubai is a descriptive cross-sectional survey. Therefore, the analysis of relations affecting unhealthy behaviors is limited to associations and not causality. A further limitation of the study was lack of precision of prevalence estimates by nationality and some other factors due to small numbers in some subgroups.

\section{Conclusion}

Application of overweight, obesity, and nutritional health programs in the schools of Dubai resulted in a lower prevalence of overweight and obesity among adolescents in schools than other countries in the region. However, overweight and obesity in adolescents remain a significant public health challenge and require further multi-sectorial health policies and programs. Despite good enforcement of school nutritional policies, adolescents are still exhibiting unhealthy nutritional behaviors such as not consuming adequate amounts of fruits and vegetables or milk and other dairy produce while consuming excessive amounts of fast food and sugar-sweetened beverages. Nutritional programs - targeting adolescents - need further enhancement and extend their scope to outside of the school community.

\section{Acknowledgments}

We appreciate the contribution of Dr. Nehad Mahdy and Dr. Badreyya Al Harmi and all staff of School Health Section - Dubai Health Authority (DHA), Ministry of Education and all participating students and schools.

\section{Statement of Ethics}

The research was conducted ethically in accordance with the World Medical Association Declaration of Helsinki and was approved by Dubai Scientific Research Ethics Committee (DSREC) No. DSREC-02/2019_10. A written signed consent from parents and adolescent assent.

\section{Conflict of Interest Statement}

The authors have no conflicts of interest to declare.

\section{Funding Sources}

None.

\section{Author Contributions}

Dr. M.A. contributed to design, tools, sampling, data management and analysis, and writing manuscript. Dr. S.F. contributed to tools, data analysis, and writing manuscript. Dr. A.A. contributed to writing manuscript. Ms. F.R. contributed to data analysis. Ms. H.J. contributed to data analysis. Dr. K.A. contributed to data analysis and writing manuscript.

\section{Data Availability Statement}

The data support the findings of this study, which are not publicly available due to the organization's administrative policy and procedures. However, the data are available from the corresponding author upon request.

\section{References}

1 Riaz U, Eun-Young L, Shanchita RK, Mark ST, Khan A. Clustering of lifestyle risk factors for non-communicable diseases in 304,779 adolescents from 89 countries: a global perspective. Prev Med. 2020 [cited 2021 Jan 21]; 131:105955. Available from: https://www.sciencedirect.com/science/article/pii/ S0091743519304384.

2 Dai H, Alsalhe TA, Chalghaf N, Riccò M, Bragazzi NL, Wu J. The global burden of disease attributable to high body mass index in 195 countries and territories, 1990-2017: an analysis of the Global Burden of Disease Study. PLoS Med. 2020;17(7):e1003198.
3 WHO. Obesity and overweight fact sheet. Geneva, Switzerland: WHO; 2020 [cited 2021 Jan 21]. Available from: https://www. who.int/news-room/fact-sheets/detail/obesity-and-overweight.

4 Al Hammadi H, Reilly J. Prevalence of obesity among school-age children and adolescents in the Gulf Cooperation Council (GCC) states: a systematic review. BMC Obes. 2019;6:3.

5 Ministry of Health \& Prevention - UAE. Global school health survey (GHSH)2015. [cited 2021 Jan 21]. Available from: https://cdn.who.int/media/docs/default- source/ncds/ncd-surveillance/datareporting/united-arab-emirates/gshs/ uae-2016-gshs-fact-sheet.pdf?sfvrsn= 7ac30a41_3.

6 Ministry of Health - Kuwait. Global school health survey (GHSH)-2015. Available from: https://www.who.int/ncds/surveillance/gshs/2015_GSHS_Kuwait_Fact_ Sheet.pdf.

7 Ministry of Health - Oman. Global school health survey (GHSH)-2015. [cited 2021 Jan 21]. Available from: https://www.who.int/ ncds/surveillance/gshs/2015_Oman_GSHS_ Fact_Sheet.pdf. 
8 Ministry of Health - Bahrain. Global school health survey (GHSH)-2016. [cited 2021 Jan 21]. Available from: https://www.who.int/ ncds/surveillance/gshs/gshs_fs_bahrain_2016.pdf.

9 Sawyer SM, Azzopardi PS, Wickremarathne $\mathrm{D}$, Patton GC. The age of adolescence... and young adulthood - authors' reply. Lancet Child Adolesc Health. 2018;2(3):e7-8.

10 Jacob C, Baird J, Barker M, Cooper C, Hanson $\mathrm{M}$. The importance of a life course approach to health: chronic disease risk from preconception through adolescence and adulthood. Southampton: University of Southampton; 2015 [cited 2021 Aug 21]. Available from: https: //www.who.int/life-course/publications/life-course-approach-to-health.pdf.

11 Reilly JJ, Kelly J. Long-term impact of overweight and obesity in childhood and adolescence on morbidity and premature mortality in adulthood: systematic review. Int J Obes. 2011;35:891-8.

12 Mokdad AH, Ford ES, Bowman BA, Dietz WH, Vinicor F, Bales VS, et al. Prevalence of obesity, diabetes, and obesity-related health risk factors, 2001. JAMA. 2003;289(1):76-9.

13 Cali AM, Caprio S. Obesity in children and adolescents. J Clin Endocrinol Metab. 2008; 93(11-1):s31-6.

14 de Onis M, Lobstein T. Defining obesity risk status in the general childhood population: which cut-offs should we use? Int J Pediatr Obes. 2010;5(6):458-60.

15 WHO. Tools for growth reference data for 5 to 19 years. Geneva, Switzerland: WHO. [cited 2021 Jan 21]. Available from: https://www. who.int/tools/growth-reference-data-for5to19-years/indicators/bmi-for-age.

16 Roberge JB, Van Hulst A, Barnett TA, Drapeau V, Benedetti A, Tremblay A, et al. Lifestyle habits, dietary factors, and the metabolically unhealthy obese phenotype in youth. J Pediatr. 2019;204:46-52.e1.

17 Kerkadi A, Sadig AH, Bawadi H, Al Thani AAM, Al Chetachi W, Akram H, et al. The relationship between lifestyle factors and obesity indices among adolescents in Qatar. Int J Environ Res Public Health. 2019;16(22):4428.

18 Fang J, Gong C, Wan Y, Xu Y, Tao F, Sun Y. Polygenic risk, adherence to a healthy lifestyle, and childhood obesity. Pediatr Obes. 2019;14:e12489.

19 Carneiro CS, Peixoto M, Mendonça KL, Póvoa T, Nascente F, Jardim T, et al. Overweight and associated factors in adolescents from a brazilian capital. Excesso de peso e fatores associados em adolescentes de uma capital brasileira. Rev Bras Epidemiol. 2017 [cited 2021 Jan 21];20(2):260-73.

20 Al-Nahas S, Wasfi AS, El Sawaf E, Mahdy NH, Al Faisal W. Dietary behaviours and body mass index among secondary school students in Dubai. Am J Food Sci Health. 2019;5(2):32-7.

21 Himes JH. Challenges of accurately measuring and using BMI and other indicators of obesity in children. Pediatrics. 2009;124 Suppl 1(1):s3-22.
22 Al Faisal W, Hussein HY, Al Behandy N. Impact of a three years multi-approach intervention on childhood and adolescent obesity at school setting. Semantic Scholar; 2018 [cited 2021 Jan 21]. Available from: https://www.semanticscholar. org/paper/Impact-of-a-Three-Years-MultiApproach-Intervention-Faisal-Hussein/aedf9c21f24c8cf1739482f84e2107fb073b4bff.

23 Taryam M, Monsef NA, Al Faisal W, Hussein HY, Suliman EA, Al Salaq A, et al. Underweight, overweight and obesity profile among Dubai population and some related factors as detected by Dubai household health survey 2014. Int J Biomed Clin Sci. 2017;2(1):1-4

24 Ahmed A. Junk food banned from every Dubai school canteen, The National [Internet]. 2011 [cited 2021 Aug 1]. Available from: https: //www.thenationalnews.com/uae/ junk-food-banned-from-every-dubaischool-canteen-1.365770.

25 Reporters. Food items banned in Dubai school canteens, Khaleej Times [Internet]. 2017 [cited 2021 Aug 1]. Available from: https: //www.khaleejtimes.com/news/uaehealth/11-food-items-banned-in-dubaischool-canteens.

26 Adegboye AR, Andersen LB, Froberg K, Sardinha LB, Heitmann BL. Linking definition of childhood and adolescent obesity to current health outcomes. Int J Pediatr Obes. 2010;5(2):130-42.

27 National Academies of Sciences, Engineering, and Medicine; Health and Medicine Division; Division of Behavioral and Social Sciences and Education; Board on Children, Youth, and Families; Committee on the Neurobiological and Socio-behavioral Science of Adolescent Development and Its Applications; Backes EP, Bonnie RJ, editors. The Promise of Adolescence: Realizing Opportunity for All Youth. National Academies Press; 2019. [cited 2021 Aug 21]. Available from: https://www.ncbi. nlm.nih.gov/books/NBK545476/.

28 DeBell M. How to analyze ANES survey data. ANES technical report series no. nes012492. Palo Alto, CA, and Ann Arbor, MI: Stanford University and the University of Michigan; 2010.

29 United Nations. Household sample surveys in developing and transition countries. New York: United Nations Publication; 2005 [cited 2021 May 6]. p. 95-121. Available from: https: //unstats.un.org/unsd/hhsurveys/pdf/ household_surveys.pdf.

30 La Coursiere DY, Bloebaum L, Duncan JD, Varner MW. Population-based trends and correlates of maternal overweight and obesity, Utah 1991-2001. Am J Obstet Gynecol. 2005;192(3):832-9.

31 Finkelstein EA, Fiebelkorn IC, Wang G. National medical spending attributable to overweight and obesity: how much, and who's paying? Health Aff. 2003;22(1):W3-219-26.

32 Al-Hazzaa HM, Abahussain NA, Al-Sobayel HI, Qahwaji DM, Alsulaiman NA, Musaiger AO. Prevalence of overweight, obesity, and abdominal obesity among urban Saudi ado- lescents: gender and regional variations. J Health Popul Nutr. 2014;32(4):634-45.

33 WHO. Increasing fruit and vegetable consumption to reduce the risk of non communicable diseases. Geneva, Switzerland: WHO; 2014 [cited 2021 Jan 21]. Available from: https://www.who.int/elena/bbc/fruit_vegetables_ncds/en/.

34 WHO. Healthy diet. Geneva, Switzerland: WHO; 2018 [cited 2021 Jan 21]. Available from: https://www.who.int/news-room/factsheets/detail/healthy-diet Accessed 2020 Jan 5.

35 Du XQ, Greenfield H, Fraser DR, Ge KY, Liu $\mathrm{ZH}, \mathrm{He}$ W. Milk consumption and bone mineral content in Chinese adolescent girls. Bone. 2002;30(3):521-8.

36 Kalkwarf HJ, Khoury JC, Lanphear BP. Milk intake during childhood and adolescence, adult bone density, and osteoporotic fractures in US women. Am J Clin Nutr. 2003;77(1): 257-65.

37 Elwood P, Pickering J, Hughes J, Fehily A, Ness A. Milk drinking, ischemic heart disease and ischemic stroke. Evidence from cohort studies. Eur J Clin Nutr. 2004;58(5):718-24.

38 Sonestedt E, Wirfält E, Wallström P, Gullberg B, Orho-Melander M, Hedblad B. Dairy products and its association with incidence of cardiovascular disease: the Malmö diet and cancer cohort. Eur J Epidemiol. 2011;26(8):609-18.

39 Liu S, Song Y, Ford ES, Manson JE, Buring JE, Ridker PM. Dietary calcium, vitamin D, and the prevalence of metabolic syndrome in middle-aged and older U.S. women. Diabetes Care. 2005;28(12):2926-32.

40 US Department of Agriculture. Nutrients and health benefits. Choose my plate. 2020 [cited 2021 Jan 21]. Available from: https://www. choosemyplate.gov/eathealthy/dairy/dairynutrients-health.

41 Marshall T. Preventing dental caries associated with sugar-sweetened beverages. J Am Dent Assoc. 2013 [cited 2021 Jan 21];144(10): 1148-1152. Available from: https://www.sciencedirect.com/science/article/abs/pii/ S0002817714605274.

42 WHO. Reducing consumption of sugarsweetened beverages to reduce the risk of childhood overweight and obesity. Geneva, Switzerland: WHO; 2014 [cited 2021 Jan 21]. Available from: https://www.who.int/elena/ titles/bbc/ssbs_childhood_obesity/en/.

43 Malik VS, Popkin BM, Bray GA, Després JP, Willett WC, Hu FB. Sugar-sweetened beverages and risk of metabolic syndrome and type 2 diabetes: a meta-analysis. Diabetes Care. 2010;33(11):2477-83.

44 Berkey CS, Rockett HR, Gillman MW, Field $\mathrm{AE}$, Colditz GA. Longitudinal study of skipping breakfast and weight change in adolescents. Int J Obes Relat Metab Disord. 2003; 27(10):1258-66.

45 Adolphus K, Lawton CL, Dye L. The effects of breakfast on behavior and academic performance in children and adolescents. Front Hum Neurosci. 2013;7:425. 